\title{
Anotaciones sobre el origen del arte coreográfico y su posible dinámica en México*
}

$\mathrm{E}$ I ARTE COREOGRáfico constituye una especialidad más sofisticada y compleja que el arte de la danza. La composición coreográfica es la geometría del acto dancístico. Como tal, puede ser concebida en la imaginación para realizarse (montarse) posteriormente, o bien, por tratarse de un fenómeno acaecido en el espacio, puede "reconstruirse" a partir de una pieza dancística ya realizada en el tiempo y el espacio. Mientras que la danza es la realización del movimiento, o sea, es el movimiento con significación, acto o secuencia que llevan a cabo uno o más cuerpos humanos en el espacio, la coreografía es la composición, el arreglo más significativo y funcional de los espacios mediante los movimientos, con intención, de uno o más cuerpos humanos. ${ }^{\mathrm{r}}$ Es decir, si bien cualquier danza "desenvuelve" una coreografía -y puede hacerlo simultáneamente a su realización aun sin una coreografía preconcebida-, la sustancia del movimiento en el espacio puede

* Este artículo es prolegómeno de un estudio más amplio y profundo sobre el desarrollo del arte coreográfico en México, desde la época prehispánica hasta nuestros días.

I. Sobre la definición del arte dancístico véanse Alberto Dallal, Cámo acercarse a la danza, México, Secretaría de Educación Pública-Plaza y Valdés, 1988, pp. II-I2, y Alberto Dallal, La danza en México Segunda parte, México, Universidad Nacional Autónoma de México, Instituto de Investigaciones Estéticas, 1989 (Estudios y Fuentes del Arte en México, Irx), pp $27-29$. 
diseñarse y "montarse" de antemano, y en esta planificación y su montaje radica cabalmente el arte coreográfico.

El origen del arte de la coreografía es tan antiguo como el rito y el espectáculo mismo, toda vez que representa el primer intento de utilizar espacios delimitados o "racionalizados" con un objetivo artístico y social concreto. Su desarrollo es paralelo a los más primitivos productos teatrales y religiosos, pero se desprende de ellos de una manera natural, en su obligación de ofrecer el desempeño maduro, profesional y especializado de un arte que posee características y valores propios: la danza. La palabra coreografía indica el "manejo" de los coros o conjuntos de histriones en el espacio escénico; en la actualidad, su concepto incluye la significación obtenida en este espacio por uno o muchos cuerpos humanos en el trance de expresar ideas, estados de ánimo, orientaciones y "sentidos" que han sido pensados, planificados y montados por el coreógrafo. Guillermina Bravo explica que, etimológicamente, coreografía es tan sólo "la escritura del coro pero [que] se puede agregar: dibujo del coro, movimiento del coro, organización de la actividad de los bailarines sobre un escenario". ${ }^{2}$

Con todo, la etimología de la palabra, referida al coro, no se aleja de la historia del desenvolvimiento de las artes del espectáculo, toda vez que el coro era protagonista del teatro griego. Sobre todo en los primeros tiempos de los ritos-espectáculos, los coros tenían tareas específicas que llegaron a codificarse y a ser consideradas básicas en el desarrollo de los ritos. Los coros desempeñaban papeles de testigos, recitadores de leyes y narradores. Desde el punto de vista de los movimientos que acompañan o dan origen a la palabra, los coros simulaban o guiaban, equilibraban, invocaban, completaban.

Al lado de la alegría del komos, del cual tomó el nombre [la comedia], se halla la parábasis, la procesión del coro que ante el público que originariamente lo rodeaba, da libre curso a mofas mordaces y personales y aun, en su forma más antigua, señaló con el dedo a alguno de los espectadores ${ }^{3}$

Desde el surgimiento de la tragedia, a partir de las fiestas y orgías dionisiacas de los machos cabríos, el coro es expresión lírica. El coro experimenta

2. Guillermina Bravo, "La composición coreográfica", en Revista Mexicana de Cultura, suplemento de El Nacional, México, 12 de julio de 1970.

3. Wernet Jaeger, Paideia: los ideales de la cultura griega, México, Fondo de Cultura Económica, 1978 , p 327 
"los tránsitos profundamente emocionales de la alegría al dolor y del dolor a la alegría. La danza es la expresión de su júbilo, de sus esperanzas, de su gratitud."4

En El origen de la tragedia. Nietzsche explica cómo incluso este gran género teatral provino, en muchos de sus aspectos formales, de la actividad y las acciones del coro. Según el filósofo, al coro trágico hay que analizarlo "en su carácter de drama primario propiamente dicho", lo cual indica que la dinámica autónoma propia del coro fue, en sus inicios, una especie de pieza dancística que realizaban los coros primitivos, a la vez que exponían, mediante voz uniforme, los textos de la representación. Como puede apreciarse, la funcionalidad del coro rebasaba su papel de "espectador ideal" o de "representante del pueblo" ante el ámbito principal — noble, divino- de la escena. El origen de la composición coreográfica estaría, si no identificado, sí estrechamente relacionado con estas maniobras del coro en los inicios del género trágico griego.

En la triada de las actividades básicas de la danza (enseñanza, ejecución, diseño-montaje coreográfico), la coreografía ha devenido fundamental fuente de propiciación y, al mismo tiempo, desafío profundo para el talento y la experiencia de los protagonistas de la danza. En la organización de la danza profesional moderna, el coreógrafo generalmente resulta el coordinador de las demás actividades básicas de la danza. Asimismo, de su talento y capacidades dependerán, en mucho, el máximo y el mínimo de las funciones eficientes de los demás integrantes del edificio dancístico.

Hay varias etapas fundamentales en la realización coreográfica que no deben ser omitidas, sobre todo en lo que se refiere al estudio teórico y especializado de ella: I) concepción, 2) creación de estructura (objetividad), 3) diseño, 4) descripción de diseño, 5) montaje y 6) realización. Es natural que estas etapas o fases de la composición coreográfica culminen en su realización, en la presentación — de preferencia profesional - ante el público, del diseño; es decir, la composición coreográfica no se halla completa sino en la "interpretación" de la obra.

Para el cabal cumplimiento de la acción coreográfica — que, como hemos visto, culmina en la acción dancística - se hace evidente la intervención de los ocho elementos de la experiencia dancística, a saber: i) el cuerpo humano, 2) el movimiento, 3) el espacio, 4) el impulso o sentido del movimiento, 
5) el tiempo, 6) el juego o relación luz-oscuridad, 7) la forma y 8) el espectador o público. ${ }^{5}$ En su desglose técnico, el diseño coreográfico no sólo aísla el tratamiento de los factores integrantes del acto dancístico (música, ritmo, lapsos o secuencias, o sea el tiempo), sino que los hace intervenit profunda y eficientemente; es decir, el diseñador o compositor debe dominar sus vías de acción y de aplicación. Sin embargo, los subelementos que el coreógrafo "manipula" o debe dominar a veces son "subproductos" de los ocho elementos o subyacen dentro de ellos. Por ejemplo, el coreógrafo concibe, sobre todo, formas, las cuales se vinculan o hallan ligadas entre sí, sostenidas por la estructura de la obra (conjunto hilado de secuencias). El movimiento en sí es "inventado" por el coreógrafo para cada instante de la obra y debe sobrevenir en porciones concretas del espacio. Lo anterior depende de cuerpos bumanos también concretos, dueños de una técnica y de un lenguaje. Este último es la summa de la experiencia adquirida, de la actitud estética asumida, de los procedimientos de capacitación involucrados por los bailarines que "trabajarán" con el coreógrafo y, además, los medios de expresión y la visión cultural asumidos por aquel que diseña la coreografía. La organización plena y eficiente de todos los elementos, subelementos y aspectos descritos se realiza cabalmente cuando la idea, el concepto, el tema (todo lo proveniente del sentido en que el coreógrafo fundamente la obra) se halla entendido en la mente del creador y éste puede "desglosarlo" con claridad.

En gran parte, la notoriedad del arte coreográfico y sus procedimientos, calidades y problemas han surgido evidentes sólo en la danza teatral, ya que las danzas tradicionales se caracterizan precisamente por sus esfuerzos por repetir y hacer perdurar diseños coreográficos originales, ancestrales; por otra parte, hasta el momento las versátiles e imaginativas danzas urbanas populares no han, por decirlo así, "tecnificado" sus vías de acción coreográficas hasta el grado de aislarlas de los espacios y variados elementos que se relacionan más con la atmósfera, el ambiente o el estatus social que con los objetivos estéticos propiamente dichos. La "funcionalidad" de las danzas populares urbanas depende en mucho de factores externos al hacer dancístico. ${ }^{6}$

El paso que dan los bailarines desde la ejecución (como papel o desempe-

5. Dallal, Cómo acercarse ..., pp. 25-48.

6. Para un estudio completo de la danza popular urbana en México, véase Alberto Dallal, El "dancing" mexicano, México, Oasis, I984 
ño único de la acción dancística) al dominio de los métodos de la enseñanza o al dominio del diseño y montaje coreográficos resulta atduo, difícil; está lleno de aprendizajes y esfuerzos de naturaleza muy distinta a los que desarrollaron durante su trayectoria los artistas exclusivamente ejecutantes. En las grandes compañías profesionales, la aparición de coreógrafos preparados y avezados, ingeniosos e imaginativos, se lleva a cabo en el transcurso de las jornadas normales de trabajo pero con base en los signos de capacidad creativa y organizativa evidentes y formales que muestran los bailarines, lo mismo durante las clases de danza que en los ensayos de las obras. El arte coreográfico es uno de los más difíciles del mundo porque no sólo exige la que podríamos llamar "capacidad de diseño" —o sea, imaginación e inventiva para las formas que han de sobrevenir en el escenario-, también requiere del dominio técnico de los procesos mediante los cuales los bailarines van a "hacer suyo" dicho diseño para "ejecutarlo" o interpretarlo en la pista, el estudio o el escenario. Es decir, además del dominio pleno del atte de la composición espacial, el coreógrafo debe aprender a expresar, durante el manejo de cada obra, cuáles son sus deseos y exigencias en relación con las interpretaciones de los bailarines. Los ejecutantes deben llegar a "interpretar" sin alejarse o rechazar el sentido que el coreógrafo le ha dado a la pieza. Si a todo lo anterior añadimos los conocimientos básicos que el coreógrafo debe poseer en torno a la técnica dancística, la música, los decorados, el vestuario, la iluminación y la literatura inherente a la "historia" o a la sucesión de imágenes que quiere narrar, nos será fácil percibir el amplio espectro de ideas, conocimientos, datos, detalles, habilidades y matices que el coreógrafo está obligado a cubrir, organizar y realizar.

El concepto de composición coreográfica, como la acción de elaborar el proyecto de una obra de danza y montarla, conlleva la idea de profesionalidad en la organización del acto dancístico. Esta idea se justifica no solamente por los conocimientos especializados a los que se somete el coreógrafo, sino también por el desenvolvimiento propio del arte de la danza, desde su origen de acciones elementales, hasta su más elaborada organización como expresión compleja del movimiento (con significación) del cuerpo humano en el espacio. Este camino, que va de lo sencillo a lo complicado, fue descrito por Nietszche de la siguiente manera:

[....] la esencia de la naturaleza ha de expresarse en forma simbólica; tequiere un mundo nuevo de símbolos, el simbolismo somático integral, no solamente el de 
la boca, del semblante, de la palabra, sino el ademán total de la danza que acciona xítmicamente sobre todos los miembros. ${ }^{\text {? }}$

El coreógrafo (en pleno dominio de la naturaleza de la danza) no sólo establece un plan de acción y dirige sus aplicaciones; es además el encargado de I) conocer a fondo las aptitudes de los bailarines para impedir la preconcepción de una danza irtealizable. A veces, el coreógrafo es asimismo 2) el maestro de los posibles intérpretes; a él se deben la sistematización de los ejercicios cotidianos, indispensables para el adiestramiento de sus cuerpos. El corégrafo también es el encargado de 3) organizar la "puesta en danza"; es decir, se ocupa de todos los aspectos de la experiencia dancística: arteglo de espacios, inclusión de diseños plásticos y adornos, funcionalidad de vestimentas, iluminación del espectáculo, horarios idóneos de trabajo, presencia y asistencia de espectadores, etcétera. Sus orientaciones devendrán, pues, en señalamientos y directivas sobre las que descansará el buen resultado de los diseños y las ejecuciones.

En las comunidades prehistóricas y antiguas, el papel del coreógrafo se hallaba unido a los menesteres del sacerdocio, la dirección política y la organización económica de los conglomerados humanos. En la medida en que las acciones dancísticas se institucionalizan y transitan —por impulso normal y natural- de lo elemental a lo complejo, los ejercicios dancísticos adquieren importancia y valor social primordiales, toda vez que las danzas van cubriendo funciones cada vez más elaboradas y complejas. Al principio imitativos e inmediatos, los movimientos del cuerpo humano en la colectividad -en comunión y comunicación eficientes- pasan a ser realizaciones nuevamente complicadas y realistas. Devienen asimismo registros operativos de las leyendas, las leyes y los acontecimientos de la comunidad. Su periodización y su naturaleza invocativa hacen surgir las danzas de celebración, mientras que la solemne división de los espacios — para sacerdotes y feligreses, para actores y espectadores, etcétera- hace sobrevenir las danzas místicas y rituales. Por su parte, la libre expresividad corporal y dancística, a la que son afectas todas las sociedades, hace que se desarrolle un tipo seglar de danzas, danzas cotidianas que se realizan de manera espontánea y que ponen énfasis en la energía gregaria, en la libre comunicación y expresión individual y colectiva de los cuerpos.

7. Friedrich Nietzsche, El origen de la tragedia a través del espiritu de la música, en Obras completas, Buenos Aires, Prestigio, 1970, vol. I, p. I5I 
El enfrentamiento de grupos y comunidades propicia el surgimiento de danzas guerreras, expansivas, agresivas . Aunque en algunas sociedades éstas siguen siendo actos rituales, el ejercicio de la guerra implica una doble personalidad de los ejecutantes guerreros, una destreza ambivalente, cargada de un peculiar sentido de la muerte, que exigirá de los contendientesintérpretes una dual presencia y un desarrollo excepcional de sus aptitudes dancísticas.

La incorporación, en la vida tribal, de las danzas mágicas y medicinales marca un hito en la historia de los ejercicios dancísticos, toda vez que la inclusión de la realización física en la estructura invocativa y curativa une al mismo tiempo elementos medicinales, ingredientes suscitadores de asimilación y metabolismo efectivos. Las danzas curativas son importantes porque localizan elementos de invocación que caen fuera de la comunidad pero que están relacionados directamente con la dolencia o el mal que se manifiesta en una parte concreta del cuerpo del paciente-penitente. En muchos casos se adhieren elementos sagrados y mágicos externos, que se incorporarán a la cultura y religión comunitarias. Este tipo de danzas permiten ejetcicios físicos que, de realizarse en espacios específicos, vendrían a comprender trazos, dibujos, rutinas "objetivables". Junto con las danzas de cazadores, devendrían las primeras danzas en las que el movimiento controlado dentro de un espacio real, localizado, ofrecería objetivos asimismo explicables, de tal manera que los diseños de las danzas podrían prepararse cabalmente, preconcebirse y montarse. O sea, resultarían los primeros "proyectos" dancísticos montables, es decit, composiciones coreográficas.

El establecimiento de los géneros en las artes del espectáculo, tanto orientales como occidentales, establece definitivamente la personalidad del coreógrafo como gran orientador y director de la estructura dancística. Las estructuras dramáticas, cómicas, épicas o melodramáticas exigirán, para su correcta erección y realización en el tiempo, la intervención de un hábil conocedor de los géneros, ya que en la existencia de ellos radica la madurez, ahora institucionalizada, de todas las artes del espectáculo, de las cuales la danza es, en ocasiones, origen o punto de partida.

La búsqueda de nuevas imágenes, generadas por el movimiento del cuerpo humano en el espacio, conduce a la creación y generación, incesantes e ininterrumpidas históricamente, de las danzas abstractas y experimentales. En efecto, los ejercicios del arte de la danza no parecen generar límites u obstáculos no prescindibles o extinguibles, y la aparición del coreógrafo como 
organizador profesional de la realización dancística produce simultáneamente el rompimiento periódico de las fórmulas del diseño aplicadas temporalmente y debidamente institucionalizadas. La posibilidad de que el coreógrafo "manipule" cuerpos diestros y de que posea los ingredientes, recursos y conocimientos suficientes para idear y montar las obras, le permite asimismo abrir caminos nuevos, experimentos, improvisar, conducir "su arte" y sus habilidades hacia formas de realización no frecuentadas con anterioridad.

En el México prehispánico, el arte coreográfico era campo exclusivo de sacerdotes, guerreros y gobernantes, de aquellos que habían acudido a las instituciones de adiestramiento y preparación de los toltecatl (artistas, personajes cultivados y especialistas): la casa de Cuicacalco, lugar en el que "los mancebos... comenzaban a bailar y danzar todos...." Como la danza era una actividad común a todo el pueblo, que se realizaba colectivamente en las variadas y múltiples celebraciones y festividades, el "guía" estaba obligado a dominar los secretos de los movimientos, ya fueran individuales o de grupo, que requerían las exigentes etapas de los ritos, desplazamientos, cantos y acompañamientos musicales. Las secuencias, acompañamientos y demás ingredientes de las "piezas" —elaboradas según cánones muy antiguos- se hallaban registrados en los usos y hábitos religiosos - primero-y en las normas de las celebraciones civiles, siempre, de todos modos, relacionadas con la incursión en tierra de las energías divinas. Si en los rituales indígenas y en las costumbres profundamente normativas de los pueblos prehispánicos se descubre un enorme grado de capacidad de codificación y legislación, estas mismas cualidades serán justamente apreciables en sus manifestaciones directamente simbólicas y creativas como la escultura, la arquitectura, la pintura, la pictografia, la plumaria y, naturalmente, la danza. En el terreno de la especialización pura, puede inferirse con elemental discernimiento que aquellas comunidades y culturas que supieron manipular espacios y procesos constructivos tan notablemente como lo muestran edificios y ciudades, procedían a aplicar "principios" estéticos que les permitían concebir, diseñar, elaborar y montar danzas colectivas con un sentido muy desarrollado del ritmo, el espacio, el movimiento y toda una serie de elementos simbólicos, plásticos y poéticos inherentes a estas manifestaciones. El sacerdote-guía-organizador de las celebraciones, procesiones, areitos y danzas fue sin duda un gran conocedor de los diseños originales y también un personaje atento y figura capaz de 
resolver los problemas y obstáculos, variaciones, combinaciones y desafíos que sorpresivamente aparecieran en la acción dancística. Pero, también, el "especialista" debía entender y atender al trayecto físico de la procesión, la conformación humana del grupo o grupos y, por así decirlo, a la geometría de la procesión, de tal manera que no se alejaran los "intérptetes" - guías y pueblo- de las etapas y secuencias originales. No sólo existía una jerarquía religiosa en cuanto a la autoridad o representación divina - $y$ sus relaciones con los dioses y el cosmos-, también existía un conocedor-especialista que, aparte de las orientaciones musicales,

[...] mandaba los meneos que había de haber en la danza y los atavios y divisas en que se habían de componer los que danzaban; también señalaba los que habían de tañer el atambor y teponaztli, y los que habían de guiar la danza o baile, y señalaba el día del baile para alguna fiesta señalada de los dioses. ${ }^{8}$

Para alcanzar estas capacidades y atribuciones, los mejores guerreros y sacerdotes, así como aquellos nobles que destacaran por su agilidad y belleza corporales, ingresaban en el Tamazcalli, "casa del hombre perfecto", lugar en el que se familiarizaban con ritmos y conocimientos, prácticas y ejercicios más profundos y notables. Como ocurría en la Grecia clásica, en las más altas culturas prehispánicas,

[...] quien no haya pasado por la escuela del gozo en los movimientos rítmicos y en la armonía de las canciones corales, es un hombre inculto. El hombre cultivado es el que posee el sentido de las bellas danzas. Éste lleva en su alma una pauta certera que le da el sentimiento infalible para lo hermoso y lo feo....?

Las antiguas culturas prehispánicas — cuya muestra más elaborada y compleja resulta ser la civilización mexica o azteca - vincularon admirablemente su producción religiosa y artística, alcanzando un alto grado de cualidad expresiva y arribando a formas simbólicas y abstractas localizables también en las corrientes más evolucionadas de las culturas occidental y oriental. Por ello resulta fácil inferir, a partir de los registros pictóricos, arquitectónicos, jeroglíficos y literarios prehispánicos, la evidente presencia de los organizado-

8. Bernardino de Sahagún, Historia general de las cosas de Nueva España, México, Porrúa, 1979, P. 47I.

9. Jaeget, op. cit., p. 1035 
res y creadores teológico-artísticos, detrás o sobre los acontecimientos y las obras colectivas e individuales del hacer social y artístico de cada comunidad. Los especialistas-coreógrafos dominaban, obviamente, no sólo el calendario de las festividades y el "tipo" de celebración; también incluían en sus conocimientos la naturaleza de las estructuras espacio-temporales que exigían los ejercicios y los métodos de selección para escoger idóneamente a "los que habían de guiar la danza o baile", y seguramente a todos sus "ejecutantes" y discípulos. La disciplina del baile era considerada socialmente importante, de tal manera que

[.... en todas las ciudades había junto a los templos unas casas grandes donde residían maestros que enseñaban a bailar y a cantar a las cuales casas llamaban cuicacally que quiere decir casa de canto donde no había otro ejercicio sino enseñar a cantar y bailar y a tañer a mozos y mozas.. ${ }^{\text {ro }}$

Aunque en el caso de la acción dancística resulta obvio que el pueblo había asimilado ya distintas modalidades y rutinas espontáneas, las exigentes formas de organización indican con claridad que intervenían "coreógrafos" adiestrados no sólo en los requerimientos de las dinámicas corporal y espacial, sino también en el orden y desenvolvimiento de las evoluciones y trazos rituales. De ahí el alto grado de perfección que alcanzaban las acciones de la danza:

[...] salían luego todos aquellos mancebos y aquellas moças así aderaçados como arriba dejo dicho de guirnaldas y sarteles a los cuellos de maiz reventados puestos en orden y en rengleras los uno frontero de los otros bailauan y cantauan y al son de un atambor que les tañían cantores en loor de aque ydolo y de la solenidad a cuyo canto todos los señores y biejos y gente principal respondían haciendo su rueda y bayle como lo tienen de costumbre teniendo a los mozos y moças en medio a cuyo espectáculo concurria toda la ciudad."

No sólo Durán: los demás cronistas e historiadores de las civilizaciones y pueblos prehispánicos también dan fe del evidente grado de desarrollo profe-

ro. Diego Durán, Ritos y fiestas de los antiguos mexicanos, edición facsimilar de la de Chavero (de I880), México, Invocación, I980, p. 227.

II. Ibidem, p. 95 
sional y de especialización que alcanzaron las actividades dancísticas antes de la llegada de los españoles. Sin embargo, resulta indispensable aclarar que la presencia del coreógrafo, como diseñador de las estructuras espacio-temporales de la danza (y de los actos y fenómenos que en ellas sobrevenían), no es la misma que la personalidad del coreógrafo que habría de especializarse y desarrollarse en la cultura "occidental", simultánea o posteriormente. En el México prehispánico, un "coordinador", o guía apto, de las acciones espaciotemporales (en las que participaban grupos e individuos de la comunidad) no sólo se sostenía mediante sus conocimientos estéticos o técnicos, no sólo determinaba los procesos y procedimientos propios de la experiencia; su intervención descansaba en el respeto de los integrantes del pueblo. Sobre él convergían también cualidades de tipo físico —en forma y en habilidadesy de tipo teligioso -conocimientos rituales y capacidades de relación subjetiva con el cosmos- - Su figura era comparable con aquellos dioses cuyas presencias y símbolos se vinculaban con elementos directos o anexos a la danza y los ejercicios físicos: proezas, ejecuciones, juegos de pelota, energía creadora, juventud, amor, sexualidad, etcétera.

Entre las hazañas del guía, el orientador, el coordinador, el coreógrafo, se halla la de registrar en su mente y su cuerpo, en el dominio de los procedimientos (técnica) del montaje, las danzas antiguas, las piezas que desde antaño alaban las glorias de la comunidad y de la nación. Así como es indispensable reconstruir las narraciones que dan nombre y consistencia a la leyenda y a la historia, resulta una exigencia montar nuevamente aquellas danzas que sitúan las etapas del surgimiento de la nación hasta la hora actual. Esta función de las danzas tiene los mismos objetivos en las culturas prehispánicas que en la cultura griega y por tanto el concepto original de la coreografía se refiere a las tareas de registro, reconstrucción y nuevo o renovado montaje, ya que "los antiguos nos han dejado muchas composiciones musicales viejas y hermosas y, para ejercicio de nuestros cuerpos, también nos han dejado bellas danzas, entre las cuales, y sin ninguna irreverencia, podemos escoger lo que cuadra y conviene a la nueva constitución que establecemos". ${ }^{2}$

En la actualidad debemos reconocer el hecho de que la tradición va conformando habilidades y talentos múltiples, silenciosos y a veces poco explícitos en el pueblo, y entender por qué en el territorio de México no sólo las 
actividades, prácticas y ejecuciones dancísticas gozan de especial evolución; también el difícil arte de la coreografía resulta trascendente en la vida cotidiana desde el punto de vista social y cultural. La coreografía es pues reconocida y necesaria acción prefesional, tanto en las distintas etapas o periodos de la historia mexicana como en las costumbres ligadas - dentro de las comunidades indígenas - a la religión, el rito, el mito, la fiesta y otros muchos aspectos de la vida comunal.

La llegada de los españoles y su imposición guerrera, política, social y cultural, trajeron consigo el derrocamiento de los más preciados valores religiosos y estéticos de las antiguas culturas. Las actividades dancísticas sufrieron paulatinamente los embates de la crítica verbal o la franca agresión. Como en los inicios de la Colonia resultaba peligroso erradicar la atractiva fastuosidad de las danzas masivas, se les permitió a los coreógrafos y a los danzantes indígenas participar en las celebraciones de Corpus Christi y en las ceremonias de adoración de los santos. Durante las tres primeras décadas posteriores a la Conquista, resultaba normal que grupos de danzantes indígenas bailaran en los atrios de las iglesias y en el interior de los mismos templos. No fue sino hasta el establecimiento y la adaptación definitivos de los coreógrafos peninsulares cuando se prohibió la participación de los danzantes indígenas, no obstante que éstos, con impresionante habilidad, habían puesto el sentido y el rumbo de sus homenajes en dirección de los santos y los personajes aledaños a la divinidad cristiana.

Aunque en los inicios de la vida colonial las danzas que las autoridades permitían practicar a los indios en el territorio conquistado eran de naturaleza y origen religioso, los frailes tuvieron buen cuidado de encauzarlas hacia celebraciones y actos cristianos, separando, por así decirlo, a los danzantes - $\mathrm{y}$ adjudicándoles categoría de "especialistas" y profesionales - del resto de la comunidad. Se establecía con toda claridad que "esta manera de danzar o bailar [la de los indios antes de la conquista] es muy diferente de nuestros bailes y danzas [...... [Las de los indios] se llaman areitos y en su lengua se llaman macehualiztli." ${ }^{13}$

Resulta notable la diferencia entre los conceptos de danza y coreografía que sostenían las actividades dancísticas indígenas con tespecto a las españolas. Sahagún indica con claridad que areito es una combinación cetemonial de danza y canto, estructura que en La Española, según Gonzalo Fernández 
de Oviedo, ${ }^{\text {I4 }}$ constituía también el registro de la expresión literaria de los acontecimientos que atañían a la tribu y a la comunidad, gracias a la intervención directa y simultánea de la voz humana. Mientras las danzas populares españolas ya se habían desprendido en algo de su naturaleza religiosa, las rutinas dancísticas indígenas permanecían incrustadas no sólo en su contexto religioso, sino también atadas a una especie de acto o experiencia totalizadora que incluía música, danza, desplazamientos en grupo - procesiones -, responsos o cánticos, sacrificios, etcétera, más cercana a la idea de espectáculo masivo que hoy se practica. De esta manera, la noción de "arte coreográfico", o sea, "el arte o ciencia de componer una danza; los movimientos, frases, ritmos, etcétera y su estructuración y ordenamiento", Is asumía en las culturas prehispánicas un conocimiento colectivo de los diseños, las formas y las distintas maneras de coordinación.

Los coreógrafos españoles trajeron a México, junto con sus rutinas, procedimientos y modos de acción, las modalidades regionales de España, las cuales se fundieron con las actitudes de criollos y mestizos, así como con buena parte de los hábitos dancísticos de los indios, los mestizos y los africanos que ya residían en la Nueva España. No sólo actitudes y "técnicas" (conjunto de procedimientos y recursos) se adaptaron y fusionaron, también se entremezclaron creativamente pasos, secuencias, obras, música, modalidades, vestuarios, etcétera, al grado de que en los escenarios novohispanos proliferó una enorme creatividad dancística y coreográfica: surgieron nuevas obras y géneros, o bien se aprovecharon las costumbres europeas para hacer surgir estructuras propias.

Durante el periodo colonial se sientan las bases de las actividades dancísticas y corcográficas del México posterior. Por una parte, se adaptan y aderezan las modalidades de la danza de salón europea y proliferan y se multiplican las danzas regionales novohispanas. Por otra parte, surgen las ricas y variadas danzas teatrales que habrán de adquirir características netamente mexicanas, mediante la adaptación de las tonadillas escénicas (de raigambte española), de los números bailados y cantados de estilo europeo, y de las obras balletísticas que traían a la Nueva España las compañías de ópera y los espectáculos del Viejo Mundo. Todo este caudal enorme y prolífico de piezas

14. Gonzalo Fernández de Oviedo, Sumario de la natural historia de Indias, México, Fondo de Cultura Económica, 1979. Véase asimismo Dallal, La danza..., pp. 88-96.

I5. Paul Love, Terminología de la danza moderna, Buenos Aires, Ediciones de la Universidad de Buenos Aires, 1964, p. 21 
se halla, en un aspecto, codificado y registrado: son las propias comunidades humanas y artísticas las encargadas de "llevar las danzas" de un lado a otro, de una región a otra distante, de un país o un continente a otro. Las piezas, en general, se remontan, se reconstruyen, y acaban por quedar recreadas. Generalmente guardan la misma música y su estructura correspondiente, pero cambian los pasos, las rutinas, las secuencias, las vestimentas. Las formas cambian paulatinamente y se adaptan al lugar, al escenario, al nuevo "paisaje" artístico, cultural y social. El coreógrafo, en estos casos de desplazamiento, resulta doblemente importante: por una parte, es quien garantiza la reconstrucción y la adaptación plenas de la obra (in situ, naturalmente) y, por otra parte, es el que mejor "adapta" o semitransforma cada pieza para que de mejor manera sea "presentada" e interpretada de acuerdo con el gusto del nuevo grupo de espectadores o de participantes.

Gran parte de las actividades creativas e interpretativas, técnicas y estéticas de la danza durante la época colonial, se imbricarán o recibirán la soterrada influencia de los conceptos y actitudes indígenas hacia la danza. Como en otras actividades y manifestaciones culturales, en la mentalidad mestiza y su ptoyección cultural intervendrán, por ejemplo, el sentido del cuerpo y del espacio, la acción creativa de la lengua o idioma, la capacidad de abstracción, la tendencia al rito, la persistencia del mito. En una palabra, intervendrá la "cultura del cuerpo" correspondiente. ${ }^{16}$ Durante el lapso colonial, los danzantes indígenas hicieron sobrevenir sus ancestrales costumbres dancísticas, ya fuera conservándolas, "aderezadas", durante sus festividades (ahora cristianas), ya fuera "disfrazándolas" mediante el uso de la simbología cristiana en las celebraciones que llevaban a cabo en los lugares más apartados del extenso territorio novohispano. \$ 
DOI: http://dx.doi.org/10.22201/iie.18703062e.1995.67.1746

ANOTACIONES SOBRE EL ORIGEN

\section{Bibliografia}

Bravo, Guillermina, "La composición coreográfica", en Revista Mexicana de Cultura, suplemento de El Nacional, México, I2 de julio de 1970.

Dallal, Alberto, Cómo acercarse a la danza. México, Secretaría de Educación Pública-Plaza y Valdés, 1988

—. La danza en México Segunda parte México, Universidad Nacional Autónoma de México-Instituto de Investigaciones Estéticas, 1989 (Estudios y Fuentes del Arte en México, IIX).

— El "dancing" mexicano. México, Oasis, 1984

Durán, Diego, Ritos y fiestas de los antiguos mexicanos. Edición facsimilar de la de Chavero (de I880), México, Invocación, 1980

Fernández de Oviedo, Gonzalo, Sumario de la natural historia de Indias. México, Fondo de Cultura Económica, I979.

Jaeger, Werner, Paideia: los ideales de la cultura griega. México, Fondo de Cultura Económica, 1978.

Love, Paul, Terminología de la danza moderna Buenos Aires, Ediciones de la Universidad de Buenos Aires, 1964."

Nietzsche, Friedrich, El origen de la tragedia a través del espiritu de la música, en Obras completas. Buenos Aires, Prestigio, 1970, vol. I.

Platón, Las leyes, o de la legislación, en Obras completas. Madrid, Aguilar, 1977.

Sahagún, Bernardino de, Historia geneval de las cosas de Nueva España México, Porrúa, 1979. 